\title{
Case Study in Project Management: A Vehicle for Business Curriculum Integration
}

\author{
Ameeta Jaiswal-Dale \\ University of St. Thomas \\ Ernest L. Owens, Jr. \\ University of St. Thomas \\ Abby Bensen \\ University of St. Thomas
}

\begin{abstract}
This case can be team-taught to combine the different elements of business education taught by individual faculty within a course in Project Management, as a partial, half-credit module within a business curriculum. This case study is written to address the feedback from prospective employers that the fresh recruits are reticent and need a long period of "internship / training / mentoring" before they are ready to be a part of the company's internal team. The case, depicting a real company undergoing substantial changes, provides the students with opportunities to gain the analytical skills developed in the study of various business disciplines, while providing the opportunity for discussion and illustration of real-life scenarios, constraints, and roadblocks. Moreover, students practice team development and process efficiencies. Instructors will teach how marketing, sales, and procurement functions impact the accounting and finance components of the project so the project scope is managed within the resources, schedule, and budget.
\end{abstract}

Keywords: curriculum integration, competency-based learning, SCRUM, Waterfall, project management, globalization of business education

\section{INTRODUCTION}

At the business school of a private Catholic university in the Upper Midwest, the job placement rate for undergraduate majors is averaging $80 \%$. However, prospective employers give feedback saying that the fresh recruits are reticent and need a long period of "internship / training / mentoring" before they are ready to be a part of the company's internal team.

This case study is written to address this feedback. Following a real company undergoing substantial changes, this case provides students with opportunities to gain the analytical skills developed in various business disciplines, while providing the opportunity for discussion and illustration of real-life scenarios, constraints, and roadblocks. 
As a part of the business curriculum, this case study's objective is to improve graduating students' confidence. The case proposes a short and meaningful way to use project management as a tool for curriculum integration and practical business education. While working on a real business project, students and company sponsors learn the skills of successful project management, a field where several business curriculums find a ready application of theory to practice.

Three authors - two instructors in Management and Finance, and a non-business graduate studentbring their individual perspectives to propose a short but effective way to coach students and faculty in the benefits of cross-functional integration via Project Management. This is the value added of the case.

\section{THE CASE}

Termadron (a pseudonym) is a 2.5 billion-dollar (USD) enterprise established in 1914. Their primary products are homeowner tools for maintenance and care. Termadron wanted to create a new lawn mower engine design that was lighter weight, was higher in power, and had better aesthetics than prior projects. One of the considerations was whether the new product should be outsourced or done in-house.

The CEO of this company was expecting to scale up in the next quarter in response to domestic and global market demand. The team under the CEO at Termadron had conducted extensive market research and defined the design parameters. The project needed to be completed in 9 months and could not exceed $\$ 750,000$ (USD). The CEO named Mr. Noordgren as the project lead. The parameters of the project were defined as:

Key attributes:

- The engine must be less than $9 \mathrm{ft}$ lbs. of torque

- The engine must have flexible storage and store in different positions

- The engine must be significantly lighter than its predecessor

- Cost reductions must be greater than 15 dollars per machine

- The engine will have newer, more attractive operating protection

- The product should be able to be produced domestically, internationally, and by select vendors

- Customers should find the product very pleasing

The project lead, Mr. Noordgren, and the project sponsor, Ms. Kindle, assembled a team composed of nine members with the following business operational functions:

- Commodities / Raw Material

- Design Engineering

- International Project Management

- Supply Chain

- Procurement

- Test Engineering

- Accounting

- Marketing

- Human Resources

The team came up with some observations and action items:

- Termadron leadership were faced with many of their projects not succeeding. In the past, the Engineering Department sent one of their members for training at the Project Management Institute (PMI). During PMI's 2010 research conference, their president stated that " 70 percent of all projects do not come in on time, on budget, or within planned resources." Similar outcomes have been experienced by Termadron.

- The CEO, an alumnus of this Midwest university, suggested the project leader have students from this Midwest university undertake a mock session to test the modalities (Waterfall vs. Agile) for project deliverables within the attributes defined by the company's project management team. 
- The project manager turned to the project training model at the Midwest university, which had the experience of working with employees of regional organizations. Hands-on project training was provided to these employees on projects within the employee's organization.

- Termadron's project management team wanted students to present the core elements of project outcomes (risk, cost, schedules, stakeholder needs, and a plan for attainment of outcomes) to the enterprise leadership.

- The student team was made up of nine members led by a student lead and a student sponsor.

The key benefit of the project training came from students learning to think and apply all business operational subjects in an interdisciplinary manner. They did this by using two tools of project management that they had been exposed to: Agile (SCRUM) and Waterfall. Establishing the distinction between Agile and Waterfall project management, students learned the phases of the Waterfall methodology_initiating, planning, executing, controlling, and closing the project - and the Agile project methodology, to complete a successful project. Students also assessed how different roles like marketing, operations, engineering, HR, procurement, accounting, and finance function within the project process. To achieve better project outcomes, instructions must be shared between all functions within an enterprise, whether the enterprise is for-profit, non-profit, governmental, international, etc.

\section{Desired Outcome for Termadron}

Given the modalities of the case, the key attributes, and the required action items, Termadron's CEO fully expected the implementation of this case at the university to produce one or more pathways helping the company to create a new engine design that is lighter weight, is higher in power, and has better aesthetics than prior projects.

\section{TEACHING NOTES}

\section{Learning Objectives}

The case serves as a repository of how different functions collaborate in Project Management, bringing various business disciplines together. Because the case is predicated on an actual project that was implemented, faculty can feel confident the outcomes are valid and useful. Figure 1 below is a diagram of the project management process, showing how faculty, sponsors, and students interact during the learning process. The arrows in Figure 1 below demonstrate PMI's tool of progressive elaboration, a tool that demonstrates the recursive nature of the conversation between the three stakeholders-faculty, sponsors, and students. 
FIGURE 1

\section{CASE STRUCTURE}

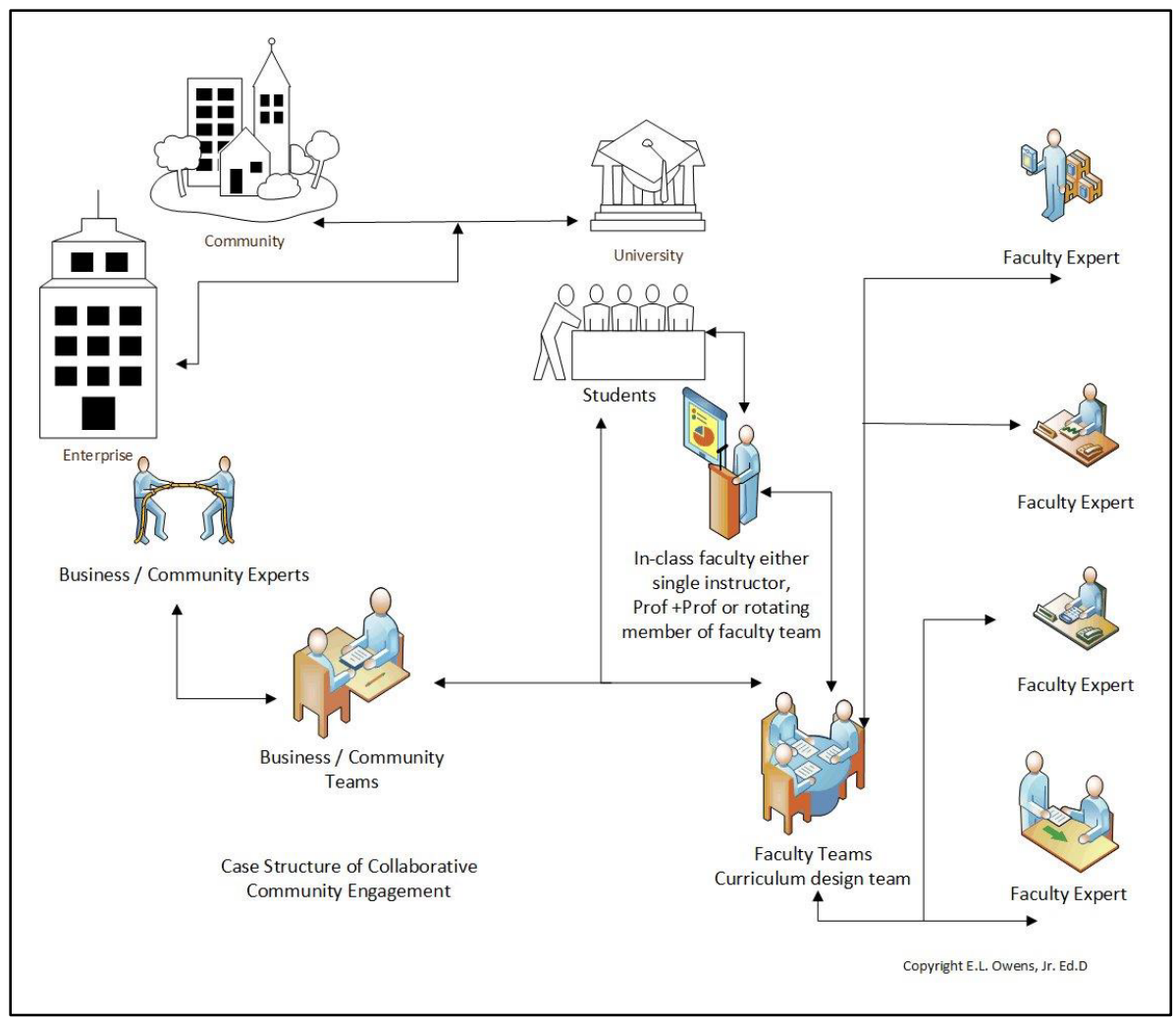

\section{Case Usage}

The Project Management course, regardless of where it is housed, has an objective of providing a concrete deliverable that draws upon various disciplines of a business curriculum, similar to the team of nine functions assembled at Termadron.

The Termadron case is brought into the classroom in the second half of the undergraduate or graduate semester, after the students are exposed to the key methodologies of Waterfall and Agile. The Waterfall method would have students experience the methodical process of defining stakeholders. In addition, they would document their requirements, cost, risk, and schedule to achieve a well-defined outcome.

\section{Discussion on Functional Areas: Theory, Analysis, and Practice}

The nine elements / team members identified in this case cover the basic courses in the business curriculum.

- Commodities / Raw Material

- Students will look for risk impacts to the project and work with industry sponsors and faculty to learn about issues with prior projects and issues that may affect the current project.

- Design Engineering

- Because design specifications are constantly changing, students need to be incorporated into the organization's review cycle, and faculty may want to be included into the organization's review process for benchmarking. 
- International Project Management

$\circ$ It is important to shed light on practices in project planning that could have international implications, such as the EU and England procedures for project validation and signoffs.

- Supply Chain

- Scheduling materials into the production cycle poses significant risk. Students and faculty must make sure the supply chain issue does not create bottle necks with availability.

- Procurement

- Knowing the impacts of Economic Order Quantity and contracting strategies such as LIFO, FIFO, and all-the-time inventory will help the teams meet project schedules.

- Test Engineering

- Faculty and sponsors can help students do some research on prior projects and show that the cost of testing is usually a great down payment on good ROI, where less waste yields better returns.

- Accounting

- The team will walk through using all the resources to enact the product through an effective, budgeted plan that serves as a tool to control the project outcomes by making impacts on cost and schedule visible to the whole team.

- Marketing

- This part of the project team will elaborate the primary, secondary, tertiary, etc. stakeholders, as well as shine a spotlight on their needs and wants. Guidance from faculty about competing needs will teach students the process of balancing ambiguous project outcomes.

- Human Resources

- Faculty can drive home to sponsors and students that more diverse staffing by ethnicity, age, sexual identity, and capabilities (like financial perspective, design capabilities, and costing, to name a few) will reduce blinders to project design and mitigate catastrophic failures.

\section{Teaching Tips}

This case is a concurrent design project (Sharifi \& Pawar, 2001) because it integrates the nine different functions, rather than creating a toss-it-over-the-wall-to-the-next-function process. This is concurrent engineering, a practical approach to business decisions that new recruits are yet to master.

Faculty can show through their research and consulting teams that working collaboratively on projects yields better results in less time than sequentially managed projects. A hybrid teaching style could successfully integrate Agile with the Waterfall method (Wyss, 2014), thereby teaching students that both methods may help with project outcomes. With many of the functions doing similar activities (such as engineering, test engineering, and commodities), the classroom experience could be crafted with three subteams focused on quantitative, qualitative, and graphical or symbolic outcomes. Students in these smaller groups could enhance the cross-functional learning, and faculty could emphasize interdisciplinary learning. In this way, even with less in-classroom participation from all functional areas, faculty could create an effective learning experience.

Through Agile, whose core ability is a SCRUM team, students can take ownership of potential solutions to refine vague deliverables. The primary SCRUM tools make the Agile methodology extremely dynamic: stating a narrative of the project through an epic (a set of user stories), a timeline defined by story points within sprints, and a continuous redefinition of the requirements through daily scrums. The impact of a successful adoption of project management via Agile at companies is clearly demonstrated by Conforto et al. (2014). 
Because Agile uses smaller teams to produce minimal viable features, the classroom can be broken into two to three sections working on the features of the product or process. The sponsor and faculty can work like product owner and SCRUM Master, respectively, bringing their respective disciplinary expertise to the project. This collaboration defines the epics, which are large chunks of deliverables from the vision of the project. The students, faculty, and sponsor can participate in a lecture about creating the backlog (refined epics). The sponsor and faculty teams should work to create a Release Plan (Dash, 2018) for the semester work.

- Sub-teams and with their faculty member can use tools like Post-It Notes to define the epic and user stories to show the overall flow of the project and feature releases.

- The whole class can review user stories, gaining confidence that they are all on the correct path. Teams will now go back to their subgroup and define story points (time estimates) for their user stories and release levels along with their sponsor as the basis of their daily classroom scrums.

- Students will act as the primary SCRUM team to define solutions and plans to achieve the features along with their sponsor. During the semester, the sponsor (product owner) and faculty (SCRUM Master) will meet separately to make sure the sprints are producing the right outcomes.

- The deliverables will be put into sprints, usually two to four weeks in duration. This will serve to timebox the work into iterative outcomes.

- With the daily scrums, the students, sponsors, and faculty can work on the changing requirements and fold in the new updates to the user stories, dynamically showing the students the nature of the SCRUM methodology.

- The sponsor can now have the teams present their Sprint Retrospectives, or lessons learned, to the organization's leadership and release the effort into production. In this model, students can see the different impact the faculty have on the SCRUMs, sprints, and feature outcomes.

\section{Teaching Activities}

Faculty should be aware that the most predictive factor of the team outcome will be how well the team shares a common goal (Flahiff, 2014). The class size determines two or more teams of nine or fewer members, each team having its own project lead and sponsor. The student teams expand on the case and its attributes to produce the deliverable for Termadron. The project lead and the project sponsor can be two or more instructors teaching project management and another area in business.

Students, relying on various courses in the business curriculum, will role play with people in the professions and set schedules in both methods. They will gain a sense of time and expectations that both methods set. Students will engage the human interaction framed in the two approaches through crossfunctional teams or intensive dedicated teams. Students will be able to tackle different styles of project risk, whether the risk is systemic or immediate. Students will also learn the concepts and rationale of Corporate Social Responsibility (Tharp \& Chadhury, 2008), which introduces them to the notion that firms have a both social and fiduciary obligation to their clients and communities. 


\section{REFERENCES}

Conforto, E.C., Salum, F., Amaral, D.C., da Silva, S.L., \& Magnanini de Almeida, L.F. (2014). Can agile project management be adopted by industries other than software development? Project Management Journal, 45(3), 21-34.

Dash, S.N. (2018). Agile Release Planning: Let's Break It Down! MPUG. Retrieved from https://www.mpug.com/agile-release-planning-lets-break-it-down/

Flahiff, J. (2014). Why some teams flop, while other teams rock! [Conference presentation]. PMI ${ }^{\circledR}$ Global Congress 2014, Phoenix, AZ, United States. Retrieved from https://www.pmi.org/learning/library/some-teams-flop-others-succeed-9285

Sharifi, S., \& Pawar, K. (2001). Product Development Strategies for Agility. In Agile manufacturing: The 21st century competitive strategy (pp. 175-192). Elsevier Science.

Tharp, J., \& Chadhury, P.D. (2008). Corporate social responsibility: What it means for the project manager [Conference presentation]. PMI Global Congress, EMEA, St. Julian's, Malta. Retrieved from https://www.pmi.org/learning/library/corporate-social-responsibility-means-projectmanager-8368

Wyss, S. (2014). Successful agile integration into existing methodologies [Conference presentation]. PMI Global Congress, EMEA, Dubai, United Arab Emirates. Retrieved from https://www.pmi.org/learning/library/agile-implementation-large-corporations-1496 